\title{
Structural and molecular insight into resistance mechanisms of first generation
} cMET inhibitors.

Gavin W. Collie, Cheryl M. Koh, Daniel J. O’Neill, Christopher J. Stubbs, Puneet Khurana, Alice Eddershaw, Arjan Snijder, Fredrik Mauritzson, Louise Barlind, Ian L. Dale, Joseph Shaw, Christopher Phillips, Edward J. Hennessy, Tony Cheung and Ana J. Narvaez.

\section{Supporting information}

Contents:
1. Supporting figures
2. Supporting tables
3. Supporting materials and methods
4. Supporting information references 


\section{Supporting figures}

Wild-type cMET

D1228V cMET

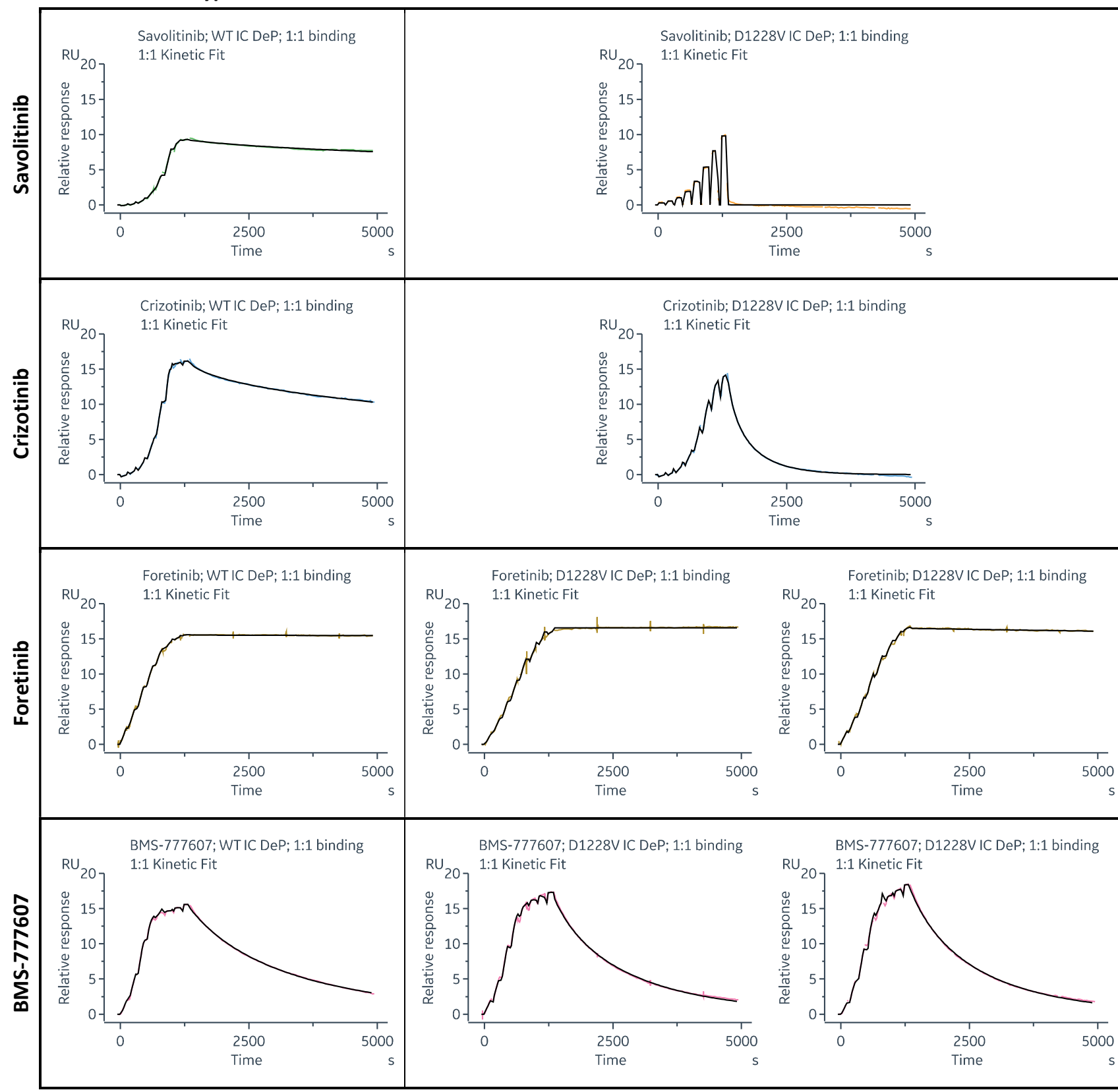

Figure S1. SPR sensorgrams showing binding of savolitinib, crizotinib, foretinib and BMS-777607 to the wild-type (left) and D1228V (right) intracellular domain of dephosphorylated cMET. Coloured lines represent the experimental data, and black lines show the best-fit to a 1:1 binding model. Affinity and kinetic parameters derived from these sensorgrams are shown in Tables S1 and S2. 
a)

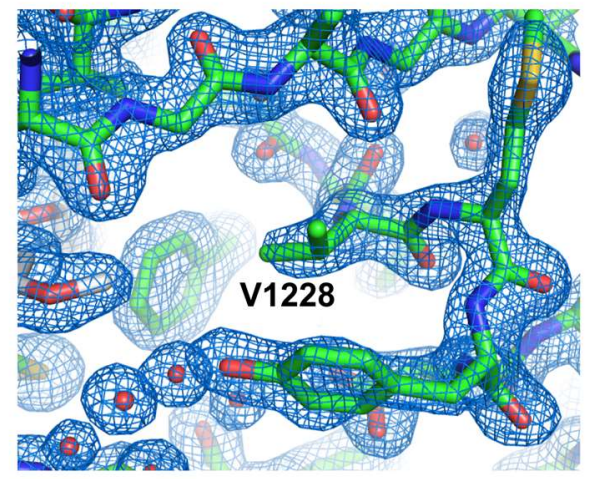

b)

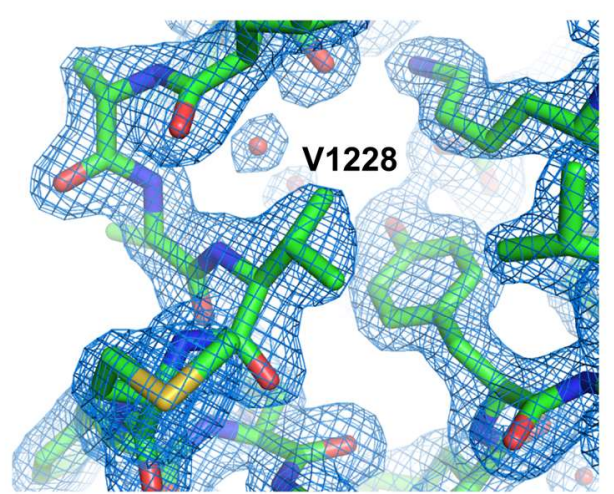

Figure S2. a) Electron density for D1228V cMET bound by foretinib centred on residue V1228. 2 $F_{o}-F_{c}$ map at $\sigma$ level 1 , resolution $1.67 \AA$. b) Electron density surrounding residue $\mathrm{V} 1228$ of the D1228V cMET-BMS-777607 complex. $2 \mathrm{~F}_{\mathrm{o}}-\mathrm{F}_{\mathrm{c}}$ map at sigma level 1.3, resolution $1.93 \AA$.

a)

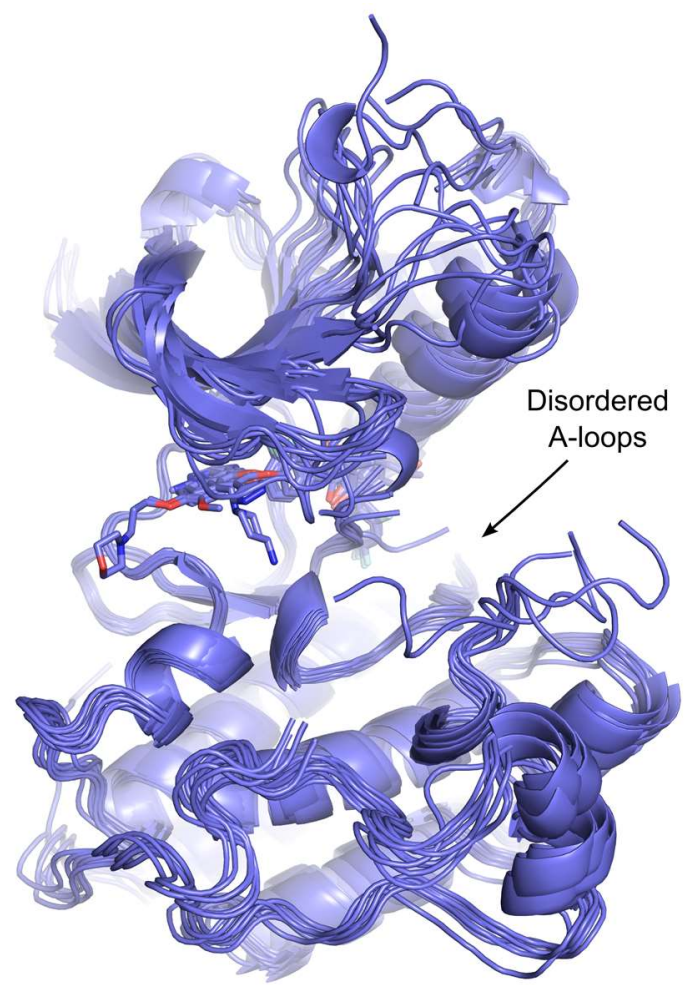

b)

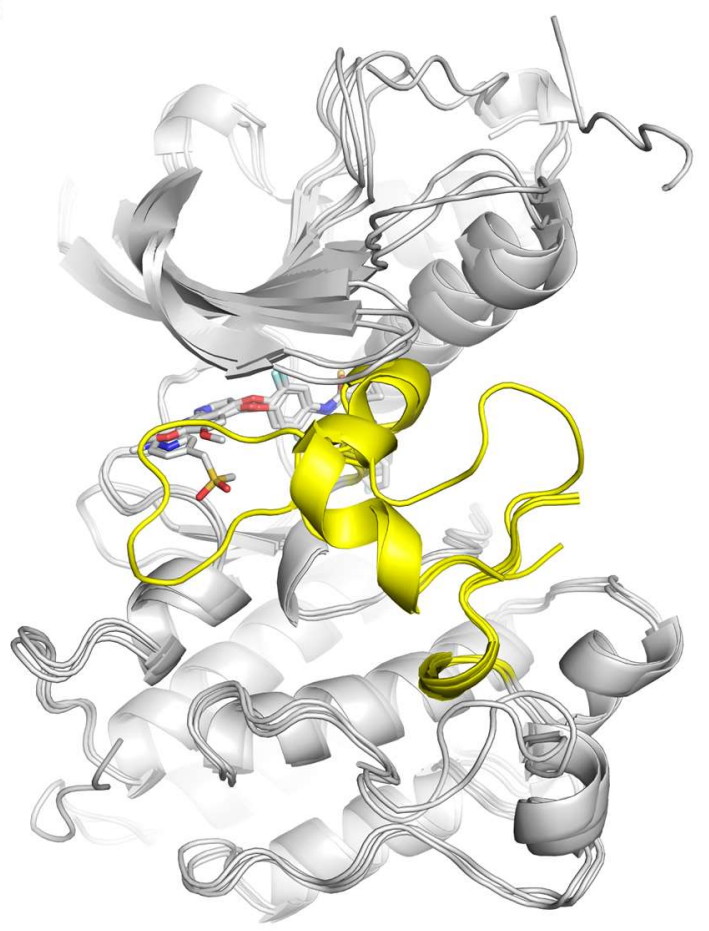

Figure S3. Comparison of type-II-cMET complexes available in the Protein Data Bank (PDB). Of the 11 crystal structures involving CMET bound by type-II kinase inhibitors that we could identify in the PDB, 8 have disordered A-loops (a) with 3 showing ordered A-loops (b) (A-loops coloured yellow in (b)). PDB entries shown here are: 3c1x, 3ce5, 3cth, 3ctj 3f82, $318 \mathrm{v}, 3 \mathrm{lq} 8$ and $4 \mathrm{eev}(\mathrm{a})$ and $3 \mathrm{vw} 8,4 \mathrm{mxc}$ and $5 \mathrm{dg} 5$ (b). 


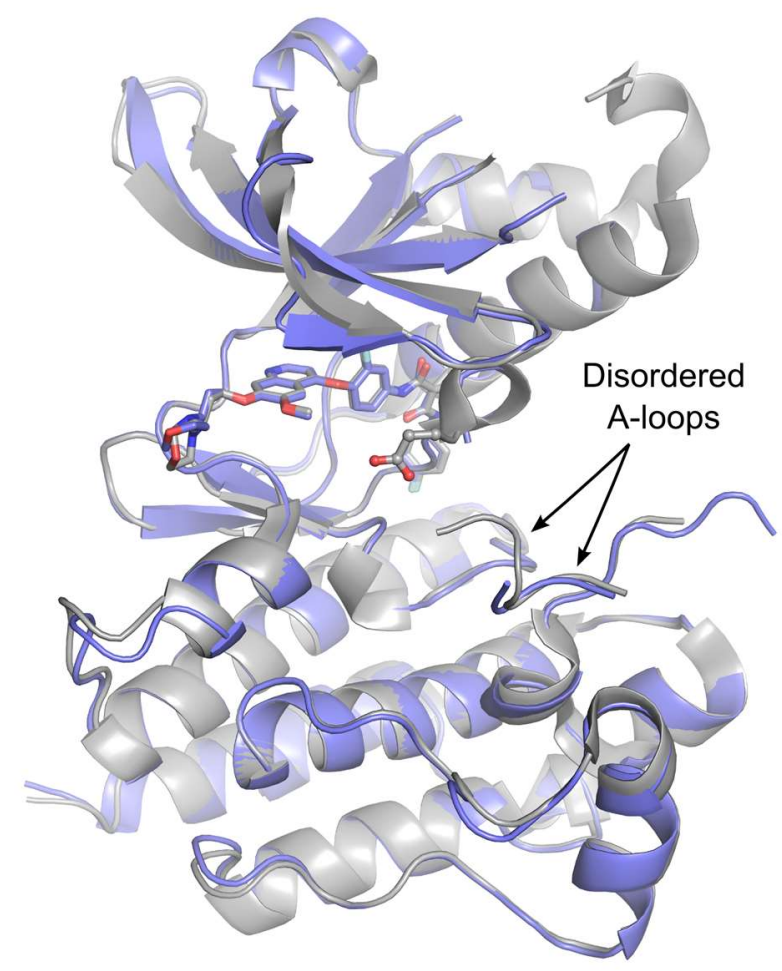

Figure S4. Structural alignment of wild-type cMET-foretinib crystal structures. Blue: crystal structure reported in this work; grey: crystal structure reported previously in alternative space group ${ }^{1}$ (PDB entry 3LQ8). RMSD of alignment: 0.857 Å for 2046 to 2046 atoms.

\section{Supporting tables}

Table S1. Summary of cellular and in vitro inhibition studies of type-I and type-II inhibitors for wild-type and D1228V cMET

\begin{tabular}{|c|c|c|c|c|c|c|c|c|}
\hline & \multicolumn{2}{|l|}{$\mathrm{pGI}_{50}\left(\right.$ Cell$\left.^{1}\right)$} & \multicolumn{2}{|c|}{ plC $_{50}\left(\right.$ Cell HTRF $\left.{ }^{2}\right)$} & \multicolumn{2}{|c|}{ pIC $_{50}$ (Biochemical $^{3}$ ) } & \multicolumn{2}{|l|}{$\mathrm{p} K_{d}\left(\mathrm{SPR}^{4}\right)$} \\
\hline cMET: & Wild-type & D1228V & Wild-type & D1228V & Wild-type & D1228V & Wild-type & D1228V \\
\hline Savolitinib & $8.03 \pm 0.10$ & $5.08 \pm 0.42$ & $8.70 \pm 0.04$ & $<4.5$ & $>8.6$ & $6.17 \pm 0.03$ & 10.2 & 5.4 \\
\hline Crizotinib & - & - & $7.58 \pm 0.14$ & $5.99 \pm 0.07$ & $>8.6$ & $>8.6$ & 8.6 & 7.9 \\
\hline Foretinib & $7.21 \pm 0.07$ & $7.28 \pm 0.14$ & $7.91 \pm 0.03$ & $7.63 \pm 0.04$ & $>8.6$ & $>8.6$ & $>9.1$ & $>8.9$ \\
\hline BMS-777607 & - & - & $6.70 \pm 0.07$ & $6.67 \pm 0.02$ & $>8.6$ & $>8.6$ & 8.7 & 8.4 \\
\hline
\end{tabular}

${ }^{1}$ Three-day proliferation assay using parental $\mathrm{NCl}-\mathrm{H} 1993$ cells expressing wild-type cMET and CRISPR/Cas9 modified NClH1993 cells expressing D1228V-mutated cMET. Values shown are average of three separate experiments \pm standard deviation. $\mathrm{pGI} 50=-\log _{10}\left(\mathrm{Gl}_{50}\right), \mathrm{M} .{ }^{2} \mathrm{HTRF}$-based measurement of potency of cMET inhibitors in $\mathrm{NCl}-\mathrm{H} 1993$ and $\mathrm{NCl}-\mathrm{H} 1993$ D1228V cMET cells. Cells were incubated with compounds for four hours before detection of phospho-cMET (Tyr1234/1235) by HTRF. Values are expressed as the mean \pm standard error of mean (s.e.m.) of at least three separate experiments. pIC $50=-\log _{10}\left(I_{50}\right)$, M. ${ }^{3} \mathrm{ADP}$-Glo kinase assay using dephosphorylated wild-type or D1228V cMET comprising full intracellular domains. All potencies, except that measured for savolitinib for D1228V cMET, are beyond the theoretical tight binding limit of the assay. Value shown is expressed as mean \pm s.e.m of three separate experiments. ${ }^{4} S P R$ experiments were performed using a Biacore $8 \mathrm{~K}$ instrument using the same wild-type and D1228V mutant cMET protein constructs as described for the biochemical ADP-Glo experiments. $K_{d}$ values for foretinib are reported as inequalities due to very slow dissociation rate constants preventing reliable measurement of koff and subsequently $K_{d} . \mathrm{p} K_{d}=-\log _{10}\left(K_{d}\right), \mathrm{M}$. 
Table S2. SPR analysis of wild-type and D1228V cMET

\begin{tabular}{|c|c|c|c|c|c|c|}
\hline & \multicolumn{6}{|c|}{ Wild-type cMET } \\
\hline & Kon $\left(M^{-1} s^{-1}\right)$ & $\operatorname{SE}\left(K_{\text {on }}\left(\mathrm{M}^{-1} \mathbf{s}^{-1}\right)\right)$ & $k_{\text {off }}\left(s^{-1}\right)$ & $\operatorname{SE}\left(\mathrm{K}_{\text {off }}\left(\mathrm{s}^{-1}\right)\right)$ & $R_{\max }(R U)$ & $K_{D}(M)$ \\
\hline Crizotinib & $2.9 \times 10^{6}$ & $2.8 \times 10^{2}$ & $6.9 \times 10^{-4}$ & $6.6 \times 10^{-8}$ & 16.0 & $2.4 \times 10^{-9}$ \\
\hline Savolitinib & $1.9 \times 10^{6}$ & $1.9 \times 10^{4}$ & $1.1 \times 10^{-4}$ & $7.5 \times 10^{-7}$ & 9.2 & $5.8 \times 10^{-11}$ \\
\hline Foretinib & $1.1 \times 10^{4}$ & $4.5 \times 10^{0}$ & $<1 \times 10^{-5}$ & - & 15.5 & $<8.9 \times 10^{-10}$ \\
\hline BMS-777607 & $2.9 \times 10^{5}$ & $2.8 \times 10^{2}$ & $6.4 \times 10^{-4}$ & $4.6 \times 10^{-7}$ & 15.2 & $2.2 \times 10^{-9}$ \\
\hline
\end{tabular}

\begin{tabular}{|c|c|c|c|c|c|c|}
\cline { 2 - 7 } \multicolumn{1}{c|}{} & \multicolumn{7}{c|}{ D1228V cMET } \\
\cline { 2 - 7 } \multicolumn{1}{c|}{} & $\mathbf{K}_{\text {on }}\left(\mathbf{M}^{-1} \mathbf{s}^{-1}\right)$ & $\mathbf{S E}\left(\mathbf{K}_{\text {on }}\left(\mathbf{M}^{-1} \mathbf{s}^{-1}\right)\right)$ & $\mathbf{K}_{\text {off }}\left(\mathbf{s}^{-1}\right)$ & $\mathbf{S E}\left(\mathbf{K}_{\text {off }}\left(\mathbf{s}^{-1}\right)\right)$ & $\mathbf{R}_{\max }(\mathrm{RU})$ & $\mathrm{K}_{\mathrm{D}}(\mathrm{M})$ \\
\hline Crizotinib & $4.1 \times 10^{5}$ & $1.2 \times 10^{3}$ & $5.8 \times 10^{-3}$ & $1.8 \times 10^{-5}$ & 15.6 & $1.4 \times 10^{-8}$ \\
\hline Savolitinib & $6.2 \times 10^{4}$ & $5.6 \times 10^{2}$ & $2.3 \times 10^{-1}$ & $2.0 \times 10^{-3}$ & 13.5 & $3.8 \times 10^{-6}$ \\
\hline Foretinib (1) & $7.0 \times 10^{3}$ & $4.9 \times 10^{0}$ & $<1 \times 10^{-5}$ & - & 16.7 & $<1.4 \times 10^{-9}$ \\
\hline Foretinib (2) & $7.6 \times 10^{3}$ & $3.7 \times 10^{0}$ & $<1 \times 10^{-5}$ & - & 16.6 & $<1.3 \times 10^{-9}$ \\
\hline BMS-777607 (1) & $2.6 \times 10^{5}$ & $2.9 \times 10^{2}$ & $1.0 \times 10^{-3}$ & $9.5 \times 10^{-7}$ & 16.8 & $4.1 \times 10^{-9}$ \\
\hline BMS-777607 (2) & $2.1 \times 10^{5}$ & $4.2 \times 10^{1}$ & $1.1 \times 10^{-3}$ & $1.8 \times 10^{-7}$ & 18.0 & $5.1 \times 10^{-9}$ \\
\hline
\end{tabular}

The sensorgrams in Figure S1 were fit to a 1:1 binding model (with mass transport), and the best-fit parameters (and their fit standard errors) are shown above. Dissociation rate constants ( $k_{\text {off }}$ ) slower than $1 \times 10^{-5} \mathrm{~s}^{-1}$ (and the related $K_{D}$ values) are reported as inequalities, as they cannot be reliably measured beyond this limit. Experiments were performed using dephosphorylated protein comprising the full intracellular domain of cMET (wild-type and D1228V; full details of protein construct used for these SPR experiments can be found below).

Table S3. X-ray data collection and refinement statistics

\begin{tabular}{|c|c|c|c|c|}
\hline & Structure 1 & Structure 2 & Structure 3 & Structure 4 \\
\hline cMET form & Wild-type & D1228V & Wild-type & D1228V \\
\hline Compound & savolitinib & foretinib & foretinib & BMS-777607 \\
\hline $\begin{array}{l}\text { Crystallisation } \\
\text { conditions }\end{array}$ & $\begin{array}{l}15 \% \text { 2-propanol, } 15 \% \\
\text { PEG4K, } 0.2 \mathrm{M} \mathrm{PCPT}^{1} \mathrm{pH} 7.5\end{array}$ & $\begin{array}{l}15 \% \text { 2-propanol, } 10 \% \\
\text { PEG4K, } 0.1 \mathrm{M} \mathrm{NaHEPES} \mathrm{pH} 8\end{array}$ & $\begin{array}{l}15 \% \text { 2-propanol, } 17 \% \\
\text { PEG4K, } 0.1 \mathrm{M} \text { NaHEPES pH } 8\end{array}$ & $\begin{array}{l}8 \% \text { ethanol, } 20 \% \text { PEG8K, } \\
0.1 \mathrm{M} \mathrm{PCPT}^{1} \mathrm{pH} 7.5\end{array}$ \\
\hline \multicolumn{5}{|l|}{ Data Collection } \\
\hline Space group & $P 2_{1} 2_{1} 2_{1}$ & $P 2_{1} 2_{1} 2_{1}$ & $P 2_{1} 2_{1} 2_{1}$ & $P 2_{1} 2_{1} 2_{1}$ \\
\hline \multicolumn{5}{|l|}{ Unit cell } \\
\hline$a, b, c(\AA)$ & $42.13,43.36,156.41$ & $42.57,80.40,91.31$ & $41.88,73.73,91.47$ & $57.96,67.81,90.05$ \\
\hline$\alpha, \beta, \gamma\left({ }^{\circ}\right)$ & $90.00,90.00,90.00$ & $90.00,90.00,90.00$ & $90.00,90.00,90.00$ & $90.00,90.00,90.00$ \\
\hline Resolution $(\AA ̊)$ & $\begin{array}{l}43.36-2.49 \\
(2.56-2.49)\end{array}$ & $\begin{array}{l}42.57-1.67 \\
(1.70-1.67)\end{array}$ & $\begin{array}{l}28.70-2.35 \\
(2.49-2.35)\end{array}$ & $\begin{array}{l}54.17-1.93 \\
(1.96-1.93)\end{array}$ \\
\hline$R_{\text {meas }}(\%)$ & $15.1(175.9)$ & $17.0(140.2)$ & $11.3(48.6)$ & $10.6(145.2)$ \\
\hline $\mathrm{CC}_{1 / 2}(\%)$ & $99.7(42.7)$ & $98.2(44.3)$ & $99.7(60.8)$ & $99.8(62.6)$ \\
\hline $1 / \sigma$ & $8.8(1.0)$ & $6.3(1.1)$ & $13.20(3.43)$ & $8.9(1.2)$ \\
\hline Completeness (\%) & $99.1(94.5)$ & $99.3(91.6)$ & $97.5(85.7)$ & $99.6(96.9)$ \\
\hline Reflections (total) & 68729 & 225396 & 73251 & 170752 \\
\hline Reflections (unique) & 10493 & 36878 & 12092 & 27276 \\
\hline Redundancy & $6.5(6.5)$ & $6.1(4.4)$ & $6.1(4.8)$ & $6.3(5.6)$ \\
\hline \multicolumn{5}{|l|}{ Refinement } \\
\hline Resolution $(\AA ̊)$ & $41.78-2.49$ & $23.45-1.67$ & $28.70-2.35$ & $23.30-1.93$ \\
\hline $\mathrm{R} / \mathrm{R}_{\text {free }}(\%)$ & $20.3 / 27.3$ & $20.1 / 24.2$ & $21.0 / 27.0$ & $21.0 / 23.0$ \\
\hline Overall B-factor $\left(\AA^{2}\right)$ & 69.55 & 24.88 & 42.38 & 35.83 \\
\hline \multicolumn{5}{|l|}{ R.m.s. deviations } \\
\hline Bond lengths $(\AA)$ & 0.010 & 0.010 & 0.010 & 0.010 \\
\hline Bond angles $\left({ }^{\circ}\right)$ & 1.07 & 0.97 & 1.08 & 0.94 \\
\hline PDB code & $6 \mathrm{SDE}$ & $6 S D C$ & 6SD9 & 6SDD \\
\hline
\end{tabular}

${ }^{1}$ PCPT = Sodium propionate, sodium cacodylate trihydrate, bis-tris propane. 


\section{Supporting materials and methods}

\section{Chemistry}

All small molecule kinase inhibitors studied in this work were either synthesised following published procedures or purchased from commercial suppliers, and were shown to be $>95 \%$ pure based on NMR, LC-MS and HPLC methods.

\section{Generation of CRISPR knock-in cells}

For genome editing, NCl-H1993 cells harbouring wt-cMET were transfected by FuGENE HD (Promega) according to the manufacturers protocol with a plasmid encoding both Cas9-T2A-GFP and a guide RNA specific to the Exon 19 insertion site (TTCTTTATCATACATGTCTC). A synthetic single-strand DNA oligo donor with homology arms to cMET Exon 19 and harbouring the required nucleotide insertion was added to the transfection at a ratio of 1:1 by weight. The oligo donor (Ultramer oligo, IDT) was designed to harbour a silent mutation in the PAM site and an additional silent mutation to aid in downstream screening of single cell clones, and has the following sequence:

\section{TTGTCCTTTCTGTAGGCTGGATGAAAAATTCACAGTCAAGGTTGCTGATTTTGGTCTCGCGAGAGTCATGTATGATAAAGAATACTAT AGTGTACACAACAAAACAGGTGCAAAGCTGCCAGTGAAGTGGATGGCTTTGG}

Transfected cells were positively selected for Cas9 expression by FACS sorting GFP positive cells and grown in the presence of $10 \mathrm{nmol} / \mathrm{L}$ savolitinib for 2 weeks before single cell cloning. Single cell clones were collated into 96 well plates, DNA extracted in Direct PCR Lysis Reagent (Viagen \#301C) with $0.4 \mathrm{mg} / \mathrm{ml}$ proteinase $\mathrm{K}$ (Viagen \#501-PL) and incubation at 85 ${ }^{\circ} \mathrm{C}$ for 40 mins. Samples were then diluted $1: 5$ in $\mathrm{dH}_{2} \mathrm{O}$ and subject to ddPCR using primers: cMET ddPCR_F TTCTATTTCAGCCACGGGTAA and CMET ddPCR_R GCAGACTTTCCAAAGCCATCC and detection probes D1228V cMET FAMTTGGTCT[C]GC[G]AGAG[T]CATGTA and wt-cMEt HEX-TCTTGC[C]AG[A]G[A]CATGTATGATA. Positive clones were confirmed by Sanger sequencing and full exome sequencing.

\section{Proliferation assay}

$30 \mu \mathrm{l}$ of $\mathrm{NCl}-\mathrm{H} 1993$ or $\mathrm{NCl}-\mathrm{H} 1993 \mathrm{cMET}$ D1228V cells $\left(5.5 \times 10^{4}\right.$ cells $\left./ \mathrm{ml}\right)$ were seeded into 384 -well plates (Corning 3712$)$ using a Wellmate Multidrop dispenser and allowed to attach overnight. The next day, the cells were Echo dosed with compounds (10 $\mathrm{MM}$ highest concentration, 10-point, half-log dilutions). The cells were incubated for 3 days, and the number of viable cells was measured using Cell Titer Glo Luminescent Viability Assay (Promega G7572).

\section{Pathway analysis by western blotting}

$\mathrm{NCl}-\mathrm{H} 1993$ and $\mathrm{NCl}-\mathrm{H} 1993 \mathrm{cMET}$ D1228V cells were treated with savolitinib or foretinib (1 $\mu \mathrm{M}$ final concentration) for 4 hours. The cells were lysed in RIPA buffer (Cell Signaling \#9086) with protease inhibitors (Sigma 5892970001) and phosphatase inhibitors (Sigma 4906845001). Protein lysates were prepared in NuPAGE LDS Sample buffer (ThermoFisher NP0008) with reducing agent, heated at $95{ }^{\circ} \mathrm{C}$ for 10 mins and separated on NuPAGE 4-12\% Bis-Tris protein gels (ThermoFisher NP0321) for 45 mins at $200 \mathrm{~V}$. The proteins were transferred to PVDF membranes (ThermoFisher LC2005) by semi-dry transfer (Biorad Trans-Blot SD Semi-Dry Transfer Cell, \#1703940) for 30 mins at 15 V. The membranes were blocked for 1 hour at room temperature with 5 \% BSA (Cell Signaling \#9998) in TBST (Cell Signaling \#9997S). The membranes were incubated with the following primary antibodies overnight (1:1000 in TBST with $1 \%$ BSA): Actin (Cell Signaling \#5057), MET (Cell Signaling \#8198), pMET (Tyr1234/1235) (Cell Signaling \#3077), AKT (Cell Signaling \#9272), pAKT (Cell Signaling \#4060). The membranes were washed $3 \times 10$ mins in TBST, and incubated with the secondary antibody, Anti-rabbit IgG, HRP linked Antibody (Cell Signaling \#7074) (1:10000 in TBST with $1 \%$ BSA) for 2 hours at room temperature. The membranes were washed $3 \times 10 \mathrm{~min}$ in TBST. Proteins were visualized using SignalFire ECL Reagent (Cell Signaling \#6883), and images were obtained on a GE ImageQuant. 


\section{HTRF assay}

$\mathrm{NCl}-\mathrm{H} 1993$ and NCl-H1993 cMET D1228V cells were plated into tissue culture treated white HiBase low volume 384 well plates (Greiner BioOne) at 800 and 3,000 cells/well respectively. Cells were allowed to adhere overnight by incubation under standard tissue culture conditions before treatment with test compounds, with additions made using an HP300 non-contact dispenser (Tecan). Following a 4 hour incubation, medium was removed from wells using a BlueWasher centrifugal plate washer (Blue Cat Bio) and $5 \mu$ of phosphor-cMET (Tyr1234/1235) HTRF lysis/detection reagent added (CisBio, AstraZeneca custom assay) using a Multidrop Combi dispenser (Thermo Fisher Scientific). Plates were lidded and incubated at room temperature in the dark for a minimum of 2 hours before detection of HTRF signal (excitation 337nm, emission 620/665nm) using a Pherastar FS multimode reader (BMG Technologies).

\section{Protein expression and purification}

For biochemical assays and SPR analysis, wild-type and D1228V cMET constructs comprising residues $956-1390$ each with an N-terminal HN-tag and avi-tag and a TEV protease recognition site were synthesised and cloned into pFastBac vectors. Protein expression was performed in Sf21 cells grown in wave-bioreactors or Thomson Optimum Growth flasks at $27{ }^{\circ} \mathrm{C}$. An increase in cell diameter was confirmed for all growths indicating successful viral infection. Sf21 cells were harvested after 48 hours by centrifugation at either at 2500 or $3400 \mathrm{~g}$ for 15 mins. Cells were lysed by freeze-thawing in lysis buffer (100 ml/L cultured cells). The lysate was clarified by $60 \mathrm{~min}$ centrifugation at $35000 \mathrm{~g}$ at $4{ }^{\circ} \mathrm{C}$. The supernatant was supplemented with $5 \mathrm{ml}$ Ni-NTA superflow incubated for 2 hours, and washed with wash buffer. After elution, cMET containing fractions were further purified using size-exclusion chromatography on a superdex 200 column. Where applicable, cMET was biotinylated using BirA biotinylation kit (BirA-500, avidity) according to protocols described by the manufacturer. Samples were dephosphorylated using $\lambda$-phosphatase, where a 1:20 molar ratio of phosphatase to cMET was applied. After confirmation of dephosphorylation by MS, CMET was purified either by captoQ purification or by an additional size-exclusion purification.

For crystallographic studies, synthetic DNA coding for residues 1038-1346 of the kinase domain of human wildtype cMET with an N-terminal HN-tag followed by a TEV protease cleavage site was cloned into a pACYC Duet vector together with DNA encoding for catYopH(164-468) ${ }^{2}$. A similar construct was made for the D1228V human cMET mutant. Plasmids were transformed into E. coli cells (LOBSTR (Kerafast EC1001) or One Shot ${ }^{\mathrm{TM}}$ BL21 (DE3) Star ${ }^{\mathrm{TM}}$ (Thermo Fisher Scientific (601003)). Proteins were produced using $5 \mathrm{~L}$ Bioreactor-fed batch cultures with IPTG induction according to methods described in Soini et al., 2008 ${ }^{3}$. In brief, $3.5 \mathrm{~L}$ minimal salt media was supplemented with 1 x BME vitamins (Sigma-Aldrich B6891), $40 \mathrm{~g}$ glucose per liter, 34 Mg/ml chloramphenicol, Struktol J 673-A antifoam and a trace elements solution with additional $\mathrm{NaSeO}_{3}, \mathrm{NaMoO}_{4}$ and $\mathrm{NiCl}_{2}$. The fermenter was inoculated at a starting OD of 0.2 and grown at a temperature of $37{ }^{\circ} \mathrm{C}$ for about 12 hours. Dissolved oxygen was maintained at $30 \%$, while a pH of 7 was maintained using $14 \%$ ammonium hydroxide solution. The feed solution contained $50 \%$ glucose/L and was supplemented with $\mathrm{MgCl}_{2}$ (approx. $7.4 \mathrm{~g} / \mathrm{L}$ ) and $34 \mu \mathrm{g} / \mathrm{ml}$ chloramphenicol. After 12 hours the temperature was lowered to $12{ }^{\circ} \mathrm{C}$ with protein production induced using $1 \mathrm{mM}$ IPTG after a 2 hour equilibration period. Cells were harvested after 48 hours by centrifugation. About $200 \mathrm{~g}$ of cells were resuspended at room temperature in $500 \mathrm{ml}$ lysis buffer $(50 \mathrm{mM}$ tris- $\mathrm{HCl} \mathrm{pH} 8.3$, $150 \mathrm{mM} \mathrm{NaCl}, 25 \mathrm{mM}$ imidazole, 10 \% (v/v) glycerol, $1 \mathrm{mM}$ TCEP, 1 mM PMSF, 0.5 \% (w/v) triton X-100 plus protease inhibitors) and subsequently passed through a Constant Systems cell disruptor at $25 \mathrm{kPsi}$. The lysate was clarified by centrifugation at $15000 \mathrm{~g}$ for 30 mins at $4{ }^{\circ} \mathrm{C}$. The $\mathrm{HN}$-tagged protein was batch bound overnight to $10 \mathrm{ml}$ of Ni-NTA superflow resin (Qiagen, 30410) and subsequently washed with wash buffer (50 mM tris- $\mathrm{HCl} \mathrm{pH} 8.3,150 \mathrm{mM} \mathrm{NaCl}, 25$ $\mathrm{mM}$ imidazole, $10 \%(\mathrm{v} / \mathrm{v})$ glycerol, $1 \mathrm{mM}$ TCEP). cMET was eluted using the same buffer supplemented with $300 \mathrm{mM}$ imidazole. After proteolytical removal of the purification tag, a subtractive IMAC was run. Samples were further purified using size exclusion chromatography on a superdex 75 gel filtration column in $20 \mathrm{mM}$ tris- $\mathrm{HCl} \mathrm{pH} 8.3,100 \mathrm{mM} \mathrm{NaCl}, 10$ $\%(\mathrm{v} / \mathrm{v})$ glycerol, and $1 \mathrm{mM}$ TCEP. CMET containing fractions were pooled and concentrated to about $10 \mathrm{mg} / \mathrm{ml}$. MS analysis confirmed that the cMET proteins were fully dephosphorylated. The final protein yield per liter of culture medium was in the range of 5-15 $\mathrm{mg}$. 


\section{Biochemical enzyme inhibition studies}

The ADP-Glo Kinase Assay (Promega) was used to determine the half maximal inhibitory concentration (IC 50 ) of crizotinib, savolitinib, foretinib and BMS-777607 for wild-type (WT) and D1228V cMET. Details of protein constructs including expression and purification can be found above. The assay buffer was common for both proteins and was composed of $50 \mathrm{mM}$ HEPES ( $\mathrm{pH}$ 7.5), $10 \mathrm{mM} \mathrm{MgCl} 2,0.1 \%$ Pluronic- 127 and $5 \mathrm{mM}$ glutathione. ATP was used at $K_{\mathrm{m}}{ }^{\text {app }}$ concentrations of $40 \mu \mathrm{M}$ and $22 \mu \mathrm{M}$ for WT cMET and D1228V cMET respectively. Poly(L-glutamic acid-L-tyrosine) was added at five times its $K_{\mathrm{m}}{ }^{\text {app }}$, i.e. $430 \mu \mathrm{g} / \mathrm{mL}$ and $850 \mu \mathrm{g} / \mathrm{mL}$ for WT cMET and D1228V cMET respectively. The phosphorylation reaction was initiated by dispensing $2 \mu \mathrm{L}$ of $10 \mathrm{nM}$ WT or D1228V protein and $2 \mu \mathrm{L}$ of substrate-mix (ATP and Poly(L-glutamic acidL-tyrosine)) for a total kinase reaction volume of $4 \mu \mathrm{L} /$ well. Following 60 minutes of incubation at room temperature, 2 $\mu \mathrm{L}$ ADP-Glo Reagent 1 was added. This was incubated for 45 minutes at room temperature to deplete the remaining ATP and to stop the kinase reaction. $4 \mu \mathrm{L}$ of ADP-Glo Reagent 2 was added and the reaction was incubated at room temperature for 30 minutes to convert the ADP product to ATP, before luminescence measurement using an Envision plate reader. Genedata software was used to fit concentration-response data to calculate $\mathrm{IC}_{50}$ values.

\section{Surface plasmon resonance}

SPR experiments were performed using a Biacore $8 \mathrm{~K}$ instrument (GE Healthcare) at $20^{\circ} \mathrm{C}$. A Series S Sensor Chip NTA (GE Healthcare) was docked into the system in $20 \mathrm{mM}$ Bicine-Na pH 7.5, $100 \mathrm{mM} \mathrm{NaCl}, 0.1 \mathrm{mM} \mathrm{TCEP}, 0.05 \%$ (w/w) Tween-20 and $1 \%(\mathrm{v} / \mathrm{v})$ DMSO. The Sensor Chip surface was conditioned with $3 \times 60$ s injections of $50 \mathrm{mM} \mathrm{NaOH} / 1 \mathrm{M} \mathrm{NaCl}$ at 30 $\mu \mathrm{L} / \mathrm{min}$ and $1 \times 60 \mathrm{~s}$ injection of $500 \mathrm{mM}$ EDTA. Proteins were diluted in running buffer to $15 \mu \mathrm{g} / \mathrm{mL}$ and immobilised onto the surface using a His-capture/couple approach. Briefly, the surface was activated using a $30 \mathrm{~s}$ injection of $0.2 \mathrm{M}$ EDC/0.05 M NHS, followed by charging of the NTA group with a 60 s injection of $500 \mu \mathrm{M} \mathrm{NiCl}$. The proteins were then injected for $120 \mathrm{~s}$, followed by $3 \times 60$ s injections of $0.5 \mathrm{M}$ ethanolamine/0.25 M EDTA to block remaining reactive groups and remove non-covalently bound protein. Reference surfaces were prepared identically but without the protein injection. All steps were performed at $20^{\circ} \mathrm{C}$, with a flow rate of $10 \mu \mathrm{L} / \mathrm{min}$. This resulted on an average of $1500 \pm 120 \mathrm{RU}$ of protein on the active flow cells.

Single-cycle kinetic experiments were performed as 8-point 2-fold dilution series from the top concentrations listed below. Each concentration of ligand was injected for $120 \mathrm{~s}$ followed by a single dissociation phase of $3600 \mathrm{~s}$ at $30 \mu \mathrm{L} / \mathrm{min}$.

\begin{tabular}{|l|l|l|}
\hline & D1228V & WT \\
\hline Crizotinib (nM) & 200 & 200 \\
\hline Savolitinib (nM) & 10000 & 100 \\
\hline Foretinib (nM) & 2000 & 2000 \\
\hline BMS-777607 (nM) & 1000 & 1000 \\
\hline
\end{tabular}

\section{Crystallography}

The purified dephosphorylated kinase domains (residues 1038-1346) of wild-type and D1228V cMET were used at concentrations of approximately $10 \mathrm{mg} / \mathrm{ml}$ for crystallisation trials. Prior to crystallisation, compounds were added to protein samples to final concentrations of $1 \mathrm{mM}$ from $100 \mathrm{mM}$ stocks in $100 \%$ DMSO, equivalent to a 3-fold molar excess of compound over protein. Co-crystals were grown at $20{ }^{\circ} \mathrm{C}$ in sitting drops composed of $100 \mathrm{~nL}$ of protein-inhibitor complex plus an equal volume of crystallisation reagent. Details of crystallisation conditions can be found in Table S3. Prior to data collection, if needed, crystals were cryo-protected in solutions composed of $75 \%$ of the crystallisation reagent supplemented with $25 \%$ glycerol. X-ray diffraction data were collected at the Diamond Light Source and SOLEIL synchrotrons. Data were processed using XDS ${ }^{4}, \mathrm{DIALS}^{5}, \mathrm{xia} 2^{6}$ and $\mathrm{CCP} 4^{7}$, and structures solved by molecular replacement using publicly available cMET structures ${ }^{1,8}$ using Phaser $^{9}$ from the CCP4 package ${ }^{7}$. Model building and refinement were performed using $\operatorname{Coot}^{10}$ and Buster (Global Phasing Ltd.), respectively, with geometry restraints for small molecule inhibitors generated using Grade (Global Phasing Ltd.). Data collection and refinement statistics plus PDB accession codes can be found in Table S3. 


\section{Supporting information references}

1. Qian, F.; Engst, S.; Yamaguchi, K.; Yu, P.; Won, K. A.; Mock, L.; Lou, T.; Tan, J.; Li, C.; Tam, D.; Lougheed, J.; Yakes, F. M.; Bentzien, F.; Xu, W.; Zaks, T.; Wooster, R.; Greshock, J.; Joly, A. H., Inhibition of tumor cell growth, invasion, and metastasis by EXEL-2880 (XL880, GSK1363089), a novel inhibitor of HGF and VEGF receptor tyrosine kinases. Cancer research 2009, 69, 8009-16.

2. Zhan, Z.; Ai, J.; Liu, Q.; Ji, Y.; Chen, T.; Xu, Y.; Geng, M.; Duan, W., Discovery of Anilinopyrimidines as Dual Inhibitors of c-Met and VEGFR-2: Synthesis, SAR, and Cellular Activity. ACS Medicinal Chemistry Letters 2014, 5, 673-8.

3. Soini, J.; Ukkonen, K.; Neubauer, P., High cell density media for Escherichia coli are generally designed for aerobic cultivations - consequences for large-scale bioprocesses and shake flask cultures. Microbial Cell Factories 2008, 7, 26.

4. Kabsch, W., XDS. Acta crystallographica. Section D, Biological crystallography 2010, 66, 125-32.

5. Winter, G.; Waterman, D. G.; Parkhurst, J. M.; Brewster, A. S.; Gildea, R. J.; Gerstel, M.; Fuentes-Montero, L.; Vollmar, M.; Michels-Clark, T.; Young, I. D.; Sauter, N. K.; Evans, G., DIALS: implementation and evaluation of a new integration package. Acta crystallographica. Section D, Structural biology 2018, 74, 85-97.

6. Winter, G., xia2: an expert system for macromolecular crystallography data reduction. Journal of applied crystallography 2010, 43, 186-190.

7. Winn, M. D.; Ballard, C. C.; Cowtan, K. D.; Dodson, E. J.; Emsley, P.; Evans, P. R.; Keegan, R. M.; Krissinel, E. B.; Leslie, A. G.; McCoy, A.; McNicholas, S. J.; Murshudov, G. N.; Pannu, N. S.; Potterton, E. A.; Powell, H. R.; Read, R. J.; Vagin, A.; Wilson, K. S., Overview of the CCP4 suite and current developments. Acta crystallographica. Section D, Biological crystallography 2011, 67, 235-42.

8. Cui, J. J.; Tran-Dube, M.; Shen, H.; Nambu, M.; Kung, P. P.; Pairish, M.; Jia, L.; Meng, J.; Funk, L.; Botrous, I.; McTigue, M.; Grodsky, N.; Ryan, K.; Padrique, E.; Alton, G.; Timofeevski, S.; Yamazaki, S.; Li, Q.; Zou, H.; Christensen, J.; Mroczkowski, B.; Bender, S.; Kania, R. S.; Edwards, M. P., Structure based drug design of crizotinib (PF-02341066), a potent and selective dual inhibitor of mesenchymal-epithelial transition factor (c-MET) kinase and anaplastic lymphoma kinase (ALK). Journal of medicinal chemistry 2011, 54, 6342-63.

9. McCoy, A. J.; Grosse-Kunstleve, R. W.; Adams, P. D.; Winn, M. D.; Storoni, L. C.; Read, R. J., Phaser crystallographic software. Journal of applied crystallography 2007, 40, 658-674.

10. Emsley, P.; Cowtan, K., Coot: model-building tools for molecular graphics. Acta crystallographica. Section D, Biological crystallography 2004, 60, 2126-32. 